Journal of Zhejiang University-SCIENCE A (Applied Physics \& Engineering)

ISSN 1673-565X (Print); ISSN 1862-1775 (Online)

www.zju.edu.cn/jzus; www.springerlink.com

E-mail: jzus@zju.edu.cn

Review:

\title{
Organic contaminants and carbon nanoparticles: sorption mechanisms and impact parameters*
}

\author{
Hong-bo PENG, Di ZHANG ${ }^{\dagger \ddagger}$, Hao LI, Chi WANG, Bo PAN \\ (Faculty of Environmental Science \& Engineering, Kunming University of Science \& Technology, Kunming 650500, China) \\ †E-mail: zhangdi2002113@sina.com \\ Received Apr. 29, 2014; Revision accepted June 26, 2014; Crosschecked July 18, 2014
}

\begin{abstract}
Carbon nanoparticles (CNPs) are novel manufactured materials with unique properties and have potential for a variety of applications. Adsorption of organic contaminants by discharged CNPs may affect the fate and transport of organic contaminants in the environment. This review summarizes the present research progress regarding organic contaminant adsorption on CNPs, and provides important information for the evaluation of the environmental behavior of organic contaminants and the risks associated with the use of CNPs. The main adsorption mechanisms involve hydrophobic interactions, $\pi-\pi$ interactions, hydrogen bonds, and electrostatic interactions. These interactions may exist simultaneously, while the controlling adsorption mechanism differs depending on the properties of both the organic contaminants and the CNPs along with environmental conditions. The status of CNPs in the environment greatly affects or even controls their characteristics for adsorption of organic contaminants. The mobility and transport of dispersed CNPs and CNP-adsorbed organic contaminants could be promoted in natural aqueous environments, potentially increasing the spread of various organic contaminants and their associated environmental risks. Investigating the adsorption mechanisms and impact parameters is vital in predicting the environmental behaviors of both organic contaminants and CNPs and their associated risks.
\end{abstract}

Key words: Organic contaminants, Environmental behaviors, Carbon nanoparticles (CNPs), Interaction mechanisms doi: 10.1631 jzus.A1400112

Document code: A

CLC number: X13

\section{Introduction}

Carbon nanoparticles (CNPs), including fullerene $\left(\mathrm{C}_{60}\right)$, graphene and carbon nanotubes (CNTs), have attracted special attention due to their unique structures. The excellent and tunable properties of CNPs such as high mechanical strength, good electrochemical stability, and useful electronic and photophysical properties (Baughman et al., 2002; Popov, 2004) have enabled increasing and widespread applications in medicine, environmental remediation,

\footnotetext{
"Corresponding author

* Project supported by the National Natural Science Foundation of China (Nos. 41303093, 41222025, and 41273138), the Program for New Century Excellent Talents in University of Ministry of Education of China, and the Recruitment Program of HighlyQualified Scholars in Yunnan Province (No. 2010CI109), China (C) Zhejiang University and Springer-Verlag Berlin Heidelberg 2014
}

energy, and communications (Arnaldi, 2013). Therefore, CNPs will inevitably enter the environment from their manufacturing, transport, use and disposal processes and may become a very important component of the environment. Recently, some researchers have reported the detection of CNPs or metal nanoparticles in various environmental media, including atmospheric water, surface water, groundwater, ocean, soil, sediment, and even drinking water (Tong et al., 2007; Wigginton et al., 2007; Handy et al., 2008; Klaine et al., 2008; Frimmel et al., 2010; Reinsch et al., 2010). The ubiquity of CNPs has raised concern among environmentalists because CNPs have been demonstrated to be toxic to various organisms (Lam et al., 2006; Handy et al., 2008; Gwinn et al., 2011; Petersen et al., 2011; Delgado and Carlo, 2013). More importantly, strong interactions between CNPs and various organic contaminants are expected due to 
their hydrophobic surfaces, which significantly alter the mobility, bioavailability, and toxicity of both CNPs and contaminants, consequently leading to unforeseen health and environmental risks (Masciangioli and Zhang, 2003; Tasis et al., 2006; Ren et al., 2011). Obviously, understanding the mechanisms of interaction between CNPs and organic contaminants is critical for environmental fate modeling and the assessment of both CNPs and organic contaminants. However, research in this area is still fragmentary and thus an overview of the mechanisms of interaction between CNPs and organic contaminants is urgently needed. In this review, we summarize and discuss three aspects of the interactions between CNPs and organic contaminants: (1) the effects of properties of $\mathrm{CNPs}$, such as their surface properties and morphology; (2) the effects of properties of contaminants, such as their molecular size, structure, and functional group; and (3) the effects of environmental conditions, such as $\mathrm{pH}$, ionic strength, co-solvents, and natural organic matter.

\section{Effects of carbon nanoparticle surface properties and structures}

\subsection{Surface properties}

Generally, for all surface properties of CNPs, the surface area always plays an important role in their interactions with organic contaminants. For example, the decreased diameter of CNTs results in increased surface area and leads to enhanced adsorption of pyrene, ofloxacin (OFL) and norfloxacin (NOR) (Yang et al., 2006; Peng et al., 2012b). The ranking of different CNPs according to the adsorption of phenanthrene determined by their surface area was: singlewalled CNTs (SWCNTs) $>$ multi-walled CNTs (MWCNTs) $>\mathrm{C}_{60}$ (Yang et al., 2006). Moreover, the major difference between SWCNTs and MWCNTs is their surface area. The surface areas of SWCNTs $\left(500-600 \mathrm{~m}^{2} / \mathrm{g}\right)$ are often larger than those of MWCNTs (100-300 $\mathrm{m}^{2} / \mathrm{g}$ ). Peng et al. (2012b) found that the adsorption of OFL and NOR on SWCNTs was significantly higher than that of MWCNTs. Other research also found that SWCNTs showed higher adsorption than MWCNTs for $17 \alpha$-ethinyl estradiol and bisphenol A (Pan et al., 2008). These results suggest that surface area is an important factor for the adsorption of organic contaminants on CNTs.

Generally, the surface areas of CNPs are lower than that of activated carbon (AC) (Cho et al., 2008). However, some CNPs, such as SWCNTs, showed comparable or even higher adsorption of organic contaminants than AC (Pan et al., 2008; Peng et al., 2012b). The high surface area of AC results from its porous structure (Wang Z.Y. et al., 2010), while outer-exposed surfaces contribute most to the surface area of SWCNTs (Yang et al., 2006). Thus, the availability of surfaces for adsorption of organic contaminants on SWCNTs would be higher than that of $\mathrm{AC}$, due to pore blocking effects. However, for planar structural molecules such as benzene, a flat surface results in better contact with CNTs, and thus adsorption increases with increasing diameter (decreased surface area) (Tournus and Charlier, 2005). Obviously, surface area alone is not enough to interpret the adsorption characteristics of organic contaminants on CNPs. Adsorption is affected by other factors, such as molecular structure, functional groups, and the morphology of CNPs.

Functional groups like $-\mathrm{OH},-\mathrm{COOH}$, and $-\mathrm{C}=\mathrm{O}$ of CNPs can be intentionally added by oxidation methods (Gotovac et al., 2007b). In addition, CNTs discharged into the environment may be oxidized in natural processes. The altered adsorption of organic contaminants on CNPs as affected by oxidation results from two characteristics. First, oxidized CNPs are more hydrophilic than pristine CNPs because the surface wettability of CNPs is enhanced by oxygencontaining functional groups, leading to increased adsorption of hydrophilic contaminants and decreased adsorption of hydrophobic contaminants (Chen W. et al., 2008; Cho et al., 2008; Shen et al., 2009). Second, the functional groups of CNPs can interact with water through hydrogen bonding, leading to the formation of water clusters, which decrease the accessibility of CNP surfaces to organic contaminants (Yang et al., 2004). Adsorption of water clusters around the O-containing groups on the surface of CNPs suppresses the adsorption of organic contaminants, due mainly to competitive adsorption for carbon surface area. Also, electrostatic repulsion might increase while the $\pi-\pi$ interactions might weak due to the increase in carboxylic groups (Sheng et al., 2010). These mechanisms result in decreased interactions between CNPs and organic contaminants, especially 
the relatively high molecular weight and low polar contaminants (Peng et al., 2003; Cho et al., 2008; Piao et al., 2008). However, hydrogen bonds could also be formed between functional groups of CNPs and contaminants, leading to enhanced interactions. For example, MWCNT-OH and MWCNT-COOH could form hydrogen bonds with 2-phenyphenol and enhance its adsorption (Zhang S.J. et al., 2010). Obviously, the adsorption of organic contaminants on oxidized CNPs is highly dependent on the properties of the organic contaminants, such as molecular size, functional groups, polarity and solubility, which will be discussed in Section 3.

Functional groups grafted on the CNT surface may affect the adsorption of organic contaminants. For example, the adsorption capacity of CNTs can be enhanced when $\beta$-cyclodextrin $(\beta-C D)$ is grafted on the CNT surface. These CNTs have very high removal ability for $\mathrm{Pb}$ (II) and 1-naphthol because the multiple hydroxyl groups and inner cores of the hydrophobic cavity in $\beta-C D$ can form complexes with metal ions and organic contaminants (Hu et al., 2010). Shao et al. (2010b) used a plasma technique to graft $\beta$-CD on the surfaces of MWCNTs and suggested that MWCNT-g-CD had a much higher adsorption capacity for the removal of polychlorinated biphenyl than that of the original MWCNTs. Results of other research with grafted polyaniline (PANI) on MWCNTs indicated that the adsorption capacity of PANI/MWCNTs was enhanced because of a strong conjugate effect between PANI and organic contaminants. Thus, PANI/MWCNTs were used to remove aniline and phenol from aqueous solutions (Shao et al., 2010a). Obviously, changes in the surface properties of CNPs greatly affect the adsorption of organic contaminants.

\subsection{Morphology}

In this section, CNTs are chosen as the major probe to elaborate the effects of morphology because of their definite structures and uniform surfaces. CNTs are known as allotropes of carbon nanomaterials and feature a seamless tubular structure formed by curling-up graphene sheets. They are classified into SWCNTs and MWCNTs according to the number of layers of graphene sheets (Iijima and Ichihashi, 1993). These CNTs contain 2 to 30 concentric cylinders and have outer diameters commonly between 2 and $50 \mathrm{~nm}$.
CNT lengths vary substantially and often range from $100 \mathrm{~nm}$ to $10 \mathrm{~mm}$ or more (Reilly, 2007). The external surfaces of CNTs are the main areas for the adsorption of organic contaminants, while the inner cavity (spaces in the innermost graphite tube) and the interwall spaces (spaces between the coaxial tubes) in the cylindrical MWCNT, generally are blocked by metal catalysts or amorphous carbons, and thus are not accessible to organic molecules (Yang and Xing, 2007). Therefore, for a single CNT, the generally available site for the adsorption of organic contaminants is its external surface (Fig. 1) (Yang and Xing, 2007).

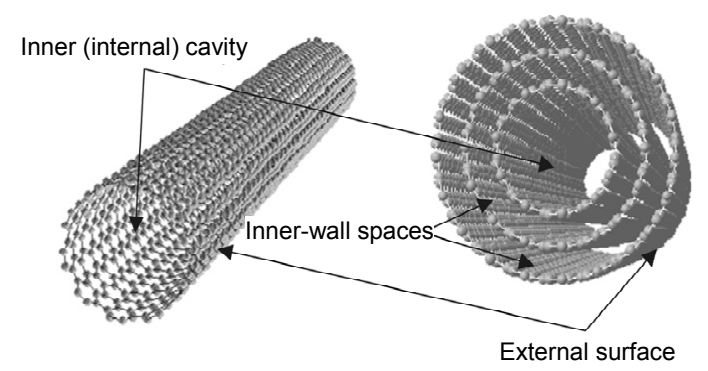

Fig. 1 Schematic structure of single-walled carbon nanotubes (left), and multi-walled carbon nanotubes (right), showing the inner cavity, external surface, and interwall spaces (Yang and Xing, 2007)

CNTs are generally found in an aggregated state in solutions because of van der Waals interactions (Zhao et al., 2002). Thus, the outer surface, inner pores of tubes, interstitial pores and groove areas between CNTs are the possible adsorption areas of CNTs (Fig. 2) (Pan et al., 2008). For organic contaminants, the inner pores of tubes are not available sorption sites because organic molecules are too large to fit into that area. Obviously, the availability of sites on CNTs for adsorption of organic contaminants is dependent on their molecular and geometrical properties and CNT morphology.

According to nitrogen adsorption analysis and theoretical calculation, the surface area of CNPs may be significantly decreased due to the aggregation of CNPs in water (Zhang et al., 2009). If CNP aggregates could be dispersed effectively, the surface area and adsorption of organic contaminants would be expected to increase. Cheng et al. (2005) found the adsorption of naphthalene and 1,2-dichlorobenzene on dispersed $\mathrm{C}_{60}$ in toluene was orders of magnitude higher than that of aggregated $\mathrm{C}_{60}$. These authors also 
investigated the adsorption of naphthalene on different aggregates of fullerene, and found that the $\mathrm{C}_{60}$ dispersion status could influence the adsorption of naphthalene significantly. Adsorption coefficients $\left(K_{\mathrm{d}}\right)$ of naphthalene on " $\mathrm{C}_{60}$ small aggregates" $\left(K_{\mathrm{d}}=10^{4.28}\right.$ $\mathrm{ml} / \mathrm{g}$ ) were higher than those on " $\mathrm{C}_{60}$ large aggregates" $\left(K_{\mathrm{d}}=10^{2.39} \mathrm{ml} / \mathrm{g}\right)$. The reason for the strong adsorption of naphthalene on " $\mathrm{C}_{60}$ small aggregates" may be that their surface area was one order of magnitude larger than that of " $\mathrm{C}_{60}$ large aggregates" (Cheng et al., 2004).

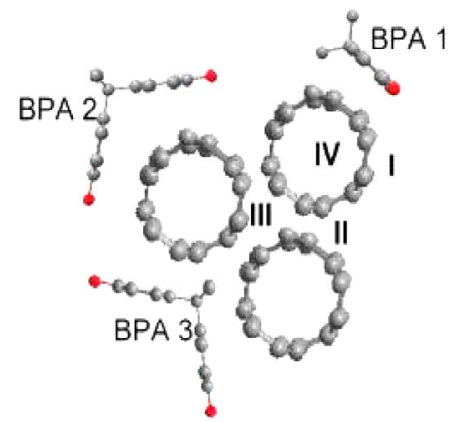

Fig. 2 Schematic diagrams of the adsorption of bisphenol A (BPA) on SWCNTs.

The numerals I, II, III, and IV indicate the possible available adsorption areas of surface, groove, interstitial spaces, and inner pores, respectively (Pan et al., 2008)

\section{Influences of contaminant structures and properties}

\subsection{Molecular size and structure}

The molecular size of organic contaminants is an important factor that affects their capacity for adsorption on CNPs. The available adsorption sites on CNPs are determined mainly by the molecular size and shape of the organic contaminant. Research results indicate that steric hindrance effects, which decrease in order of decreasing molecular size, prevent access of organic contaminants to some sorption sites on CNT surfaces. Obviously, smaller-sized molecules have a greater number of available sites on CNTs and, therefore, higher adsorption in comparison with larger-sized molecules (Wang Y.F. et al., 2010).

The effects of molecular structure and shape can be illustrated well by comparing the adsorption of phenanthrene and tetracene on SWCNTs. The higher adsorption of tetracene results from the better suitability of the tetracene molecule (a long four-ring molecule with a large $\pi$ electron system) to the surface of SWCNTs than the phenanthrene molecule (Gotovac et al., 2007c; Liu et al., 2008). A model of the contact of phenanthrene and tetracene with the SWCNT surface is illustrated in Fig. 3 (Gotovac et al., 2007a). At least one of the benzene rings of the phenanthrene molecule cannot make complete contact with the curved SWCNT surface because of its rectangular structure, while the tetracene molecule fits the curved SWCNT surface better, due to its linear structure. This means that tetracene with 4 aromatic rings makes better contact with the SWCNT surface than phenanthrene with 2.5 aromatic rings. Therefore, a remarkable difference between the adsorption of phenanthrene and tetracene is observed. Similar results were found for the adsorption of 1-naphthol and 2-phenylphenol on CNTs. 1-naphthol has two fused benzene rings, but the two benzene rings of 2-phenylphenol are separated. The fused benzene rings can match the carbon ring array of the tubes better than the separated rings, leading to a higher adsorption of 1-naphthol on CNTs (Lin and Xing, 2008a).
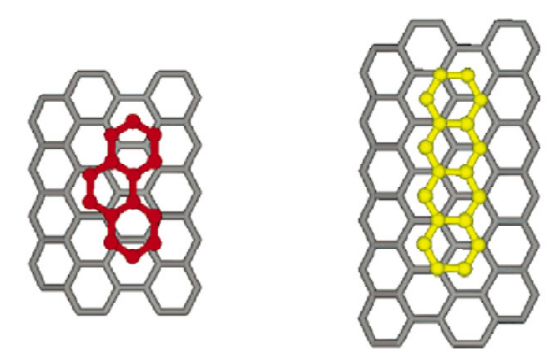

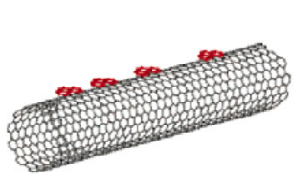

(a)

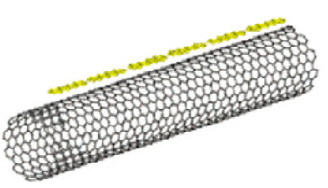

(b)
Fig. 3 Adsorption models of phenanthrene (a) and tetracene (b) on SWCNTs.

Molecules are assumed to be adsorbed such that the molecular axis is parallel to the nanotube axis (Gotovac et al., 2007a)

\subsection{Molecular functional groups}

Organic contaminants with different functional groups have different interactions with heterogeneous CNPs. For example, adsorption affinity increases in the order of nonpolar aliphatic $<$ nonpolar aromatics $<$ nitroaromatics for a given CNT (Chen et al., 2007). Cyclohexane cannot form $\pi-\pi$ interactions and 
hydrogen bonds with CNPs because it has no functional groups. It is widely recognized that the effect of molecular functional groups on adsorption of organic contaminants by CNTs is by $\pi-\pi$ electrondonor-acceptor (EDA) interaction (Gotovac et al., 2006; Chen et al., 2007). The strength of EDA interaction is greatly dependent on the functional groups attached to the benzene rings of organic contaminants Previous research noted that adsorption of 2-naphthol was higher than that of 2,4-dichlorophenol on CNTs because the EDA interaction was more prominent for 2-naphthol. The stronger EDA interaction of 2-naphthol was probably due to two reasons. First, the electron density in the benzene rings of 2-naphthol was greater than that of 2,4-dichlorophenol, because 2,4-dichlorophenol contains two chlorine groups with strong electron-withdrawing ability. In addition, 2-naphthol with two benzene rings has much stronger $\pi$-electron-conjugating potential than 2,4dichlorophenol with one benzene ring (Chen W. et al., 2008).

The adsorption of organic contaminants with $-\mathrm{OH}$ and $-\mathrm{COOH}$ functional groups on CNPs may be enhanced via hydrogen bonds (Vermisoglou et al., 2007; van Wieren et al., 2012). Yang et al. (2008) indicated that the adsorption affinity of phenol or aniline on CNPs was enhanced with their substituted groups at a given position in the following order: nitro group $>$ chloride group $>$ methyl group, due to differences in the ability to form hydrogen bonds (Yang et al., 2008). The ability to form hydrogen bonds is also affected by the position of functional groups. For example, the substitution of hydroxyl in the metaposition for phenol gave higher adsorption than substitution in the ortho- or para-position (Liao et al., 2008).

The polarity of organic contaminants is also greatly affected by molecular functional groups, and the dominant interactions between CNPs and polar or nonpolar contaminants are significantly different. For example, the adsorption of polar organic contaminants increases with increased CNP oxygen content because of the enhanced hydrogen bonding or $\pi-\pi$ EDA interactions. However, the adsorption of nonpolar organic contaminants decreases with increased CNP oxygen content due to decreased hydrophobic interactions (Pan and Xing, 2008).

\subsection{Mechanisms of interaction between contami- nants and carbon nanoparticles}

The above studies suggest that various mechanisms such as hydrophobic, electrostatic, hydrogen bonding, and the $\pi-\pi$ EDA mechanism play roles in the adsorption of organic contaminants on CNPs (Table 1) (Gotovac et al., 2007c; Pan et al., 2008; Pan and Xing, 2008; Ji et al., 2009). Among these interactions, hydrophobic interaction has been used to interpret the sorption of hydrophobic organic contaminants (HOCs) by CNPs, because the surfaces of CNPs are hydrophobic (Gotovac et al., 2006; 2007c; Yang et al., 2006). Electrostatic interaction may be the dominant interaction for the adsorption of charged organic contaminants on CNPs (MacKay and Vasudevan, 2012), such as the adsorption of fluoroquinolone antibiotics (OFL and NOR) on CNTs, as affected by $\mathrm{pH}$ (Wang et al., 2009; Peng et al., 2012b). Hydrogen bonds can form between CNPs and organic contaminants if both chemicals and CNPs have certain functional groups, such as $-\mathrm{OH},-\mathrm{COOH},-\mathrm{F}$, and $-\mathrm{NH}_{2}$ (Vermisoglou et al., 2007; van Wieren et al., 2012). $\pi-\pi$ interaction has also been used to interpret the adsorption of organic contaminants with a benzene ring or $\mathrm{C}=\mathrm{C}$ double bond on the $\mathrm{CNP}$ surface (Chorover et al., 1999; Kulshrestha et al., 2004; Woods et al., 2007). These mechanisms may act simultaneously, and different mechanisms may respond differently to changes in CNP properties. For example, if hydrogen bonding is the controlling adsorption mechanism, sorption of organic contaminants may increase as the oxygen content of CNPs increases. However, if hydrophobic interaction is the predominant mechanism, sorption of organic contaminants may decrease as the oxygen content of CNPs increases. Thus, the relative contribution of individual mechanisms to overall adsorption is vital to predict interactions between contaminants and CNPs. However, present studies generally emphasize that various adsorption mechanisms simultaneously affect the sorption of organic contaminants on CNPs, but do not distinguish the controlling sorption mechanism or propose methods to quantify the relative contribution of a given mechanism. Therefore, we considered some methods to estimate the relative contribution of an individual mechanism, as follows: (1) $K_{\mathrm{HW}}$-normalized adsorption coefficients $K_{\mathrm{d}}$ $\left(K_{\mathrm{d}} / K_{\mathrm{HW}}, K_{\mathrm{d}}\right.$ is the the total interactions apparent adsorption coefficient and $K_{\mathrm{HW}}$ is the $n$-hexadecane 
Table 1 Effects of various interactions on the adsorption of organic contaminants by CNPs

\begin{tabular}{|c|c|c|}
\hline Adsorbent & Adsorption mechanisms and their functions & Reference \\
\hline MWCNTs & Electrostatic interaction and hydrogen bond increase adsorption & (Yang et al., 2012) \\
\hline MWCNTs & Solution $\mathrm{pH}$, ionic strength, and solvent affect sorption & (Liu et al., 2012) \\
\hline MWCNTs & $\begin{array}{l}\text { Hydrophobic interactions induce adsorption; } \pi-\pi \text { electron donor-acceptor } \\
\text { interaction increases adsorption }\end{array}$ & (Ji et al., 2009) \\
\hline $\begin{array}{l}\text { Titanium oxide } \\
\text { nanoparticles }\end{array}$ & $\begin{array}{l}\text { Electrostatic interactions: electrostatic repulsion decreases adsorption while } \\
\text { electrostatic attraction increases adsorption, surface complexation increases } \\
\text { adsorption }\end{array}$ & $\begin{array}{l}\text { (van Wieren et al., } \\
\text { 2012) }\end{array}$ \\
\hline SWCNTs & Large surface area induces adsorption & (Zhang X. et al., 2010) \\
\hline
\end{tabular}

water partition coefficient) could be used to screen out the hydrophobic effect (Chen et al., 2007), enabling the effect of other mechanisms to be easily determined. (2) Comparison of adsorption coefficients of different organic contaminants on a given CNP or of a given contaminant on CNPs with different functional groups will provide important information about the relative contribution of a given mechanism. (3) Conducting adsorption experiments using organic solvents with different polarities may provide more insight to understand the relative contribution of hydrophobic interactions or other adsorption mechanisms.

On the other hand, a variety of computational studies have been devised to predict the sorption mechanisms for organic contaminants on CNPs. Tournus et al. (2005) used ab initio methods to investigate the $\pi$-stacking interaction of the planar polycyclic aromatic hydrocarbons benzene, pyrene and azulene with SWCNTs. Umbuzeiro et al. (2011) applied computational modeling to 1-nitropyrene and MWCNTs and found that physisorption at defect free MWCNT regions appeared to be the main interaction mechanism. Fagan et al. (2004) used calculations from first-principles to study the structural and electronic behavior of the interaction between 1,2dichlorobenzene (DCB) and SWCNTs. The results indicated that the DCB interacted weakly with a perfect SWCNT surface but slightly more strongly with a structurally vacant SWCNT surface. Zou et al. (2012) found that $\pi-\pi$ interactions contributed about $24 \%$ to between organic contaminants and CNTs when they computed the adsorption of cyclohexane, benzene derivatives, and polycyclic aromatic hydrocarbons on $(8,0)$ SWCNTs by density functional theory. Thus, theoretical calculation incorporated in experimental study can provide a better understanding of the interaction between organic contaminants and CNPs.

\section{Sorption of organic contaminants on car- bon nanoparticles as affected by environ- mental conditions}

The effects of water chemistry on the adsorption of organic contaminants on CNPs have been well documented. For example, Chen G.C. et al. (2008) systematically studied the effects of $\mathrm{pH}$, ionic strength, and the presence of humic acids (HAs) or heavy metal ions on organic contaminant-CNT interactions. They found that $\mathrm{Cu}^{2+}$ or ionic strength slightly affected the adsorption affinities of organic contaminants, and HA reduced adsorption by $29 \%-57 \%$ for CNTs. They also indicated that the adsorption of naphthalene was not affected by changing the $\mathrm{pH}$ from 2 to 11 , but the adsorption of 1,3-dinitrobenzene and 1,3,5-trinitrobenzene increased 2-3 times from $\mathrm{pH} 2$ to 11 . Other studies also demonstrated that $\mathrm{pH}$ was an important factor affecting the adsorption of organic contaminants on CNTs. The formation of water clusters around oxygen-containing groups on the CNT surface results in decreased adsorption of 1,2-dichlorobenzene on CNTs when the $\mathrm{pH}$ exceeds 10 (Peng et al., 2003). Lu et al. (2005) also indicated that oxygen groups were ionized at higher $\mathrm{pH}$ and thus, could adsorb more water molecules. Water clusters forming on these groups occupy adsorption sites on the CNT surface and thus result in less adsorption of trihalomethanes when the $\mathrm{pH}$ exceeds 7. Previous discussion concluded that multiple mechanisms may exist simultaneously for the adsorption of organic contaminants on CNPs. Obviously, these environmental conditions or factors will "wedge into" these mechanisms and thereby alter the behavior of organic contaminants in real environments. Thus, the effects of water chemistry, such as $\mathrm{pH}, \mathrm{HA}$, ionic strength, and the presence of heavy metal ions, on the adsorption of organic 
contaminants on CNPs should be considered in this review.

\section{$4.1 \mathrm{pH}$}

The species of ionizable organic contaminants are changed by changing $\mathrm{pH}$, which results in variation in the apparent characteristics and mechanisms of adsorption on CNPs. For example, the solubility and ionization of some organic contaminants like herbicides and resorcinol increases with increasing $\mathrm{pH}$, leading to decreased adsorption on CNPs due to decreased hydrophobicity (Biesaga and Pyrzynska, 2006; Liao et al., 2008). In addition, electrostatic attractive or repulsive interactions are important for the adsorption of organic contaminants as affected by $\mathrm{pH}$. When $\mathrm{pH}_{\mathrm{zpc}}$ (zero point of charge for CNPs)> $\mathrm{pH}>\mathrm{p} K_{\mathrm{a}}$ (ionizable organic contaminants), organic contaminants will show high adsorption because of the electrostatic attraction between negatively charged contaminants and positively charged CNPs. On the other hand, when $\mathrm{pH}>\mathrm{p} K_{\mathrm{a}}$ and $\mathrm{pH}_{\mathrm{zpc}}$ or $\mathrm{pH}<$ $\mathrm{p} K_{\mathrm{a}}$ and $\mathrm{pH}_{\mathrm{zpc}}$, the adsorption of contaminants on CNPs is low because of the electrostatic repulsion between adsorbates and adsorbents. For example, when $1.8<\mathrm{pH}<11.0$, perfluorooctanoic acid (PFOA) is negatively charged due to its $\mathrm{p} K_{\mathrm{a}}$ of -0.5 . The $\mathrm{pH}_{\mathrm{zpc}}$ of $0.08 \%$ oxygen content MWCNTs is 2.13 . Thus, its surface is generally negatively charged and the negative charge will increase with increasing $\mathrm{pH}$. The stronger electrostatic repulsion force between negatively charged PFOA molecules and CNPs results in weak adsorption (Li et al., 2011). At pH 5.0 or 6.0, OFL or NOR shows the highest adsorption, probably because of electrostatic attraction between negatively charged CNPs and positively charged OFL or NOR molecules (Peng et al., 2012a). Zhang D. et al. (2010) investigated the $\mathrm{pH}$-dependent adsorption of sulfamethoxazole (SMX) on CNTs and different dominant mechanisms were identified at different $\mathrm{pH}$ values (Fig. 4). The same discussion could be applied to other organic pollutants.

\subsection{Water-organic cosolvents}

The species of organic contaminants and their solubility and mobility differ in different organic solvents or cosolvents (Park et al., 2002). Cosolvents have been noted to increase organic contaminant solubility. Increased solubility results in decreased

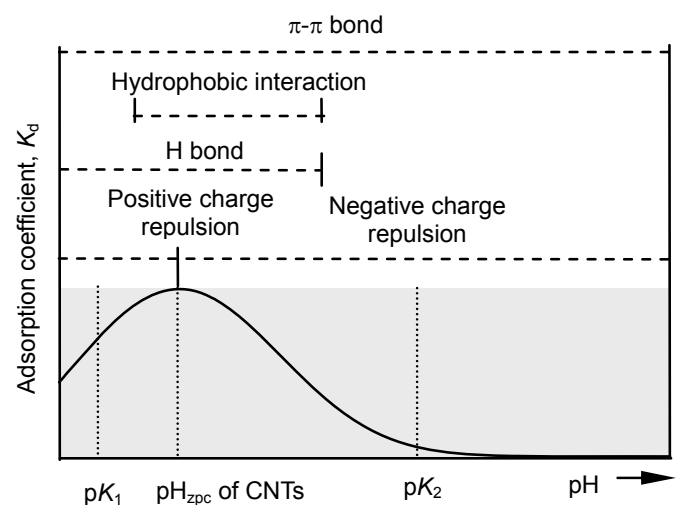

Fig. 4 Possible adsorption mechanisms for SMX on CNTs at different $\mathrm{pH}$ values.

$K_{\mathrm{d}}$ decreases with increasing $\mathrm{pH}$ when $\mathrm{pH}>\mathrm{pH}_{\mathrm{zpc}}$ and decreases with decreasing $\mathrm{pH}$ when $\mathrm{pH}<\mathrm{pH}_{\mathrm{zpc}}$, because of electrostatic repulsions. At a $\mathrm{pH}$ of around $\mathrm{pH}_{\mathrm{zpc}}$, various adsorption mechanisms (such as hydrophobic interaction, $\pi-\pi$ bonding and hydrogen bonding) contribute to overall SMX adsorption (Zhang D. et al., 2010)

sorption of contaminants (Clark II et al., 2003). Thus, investigating the adsorption of organic contaminants on CNPs in organic solvents or cosolvents could provide a new research perspective to understand their sorption mechanisms.

Methanol is a water-like, polar organic solvent. It is used as a common cosolvent in most studies because it is completely miscible with water (Bouchard, 1998). Previous studies investigated both the solubility and sorption of OFL and NOR on CNTs in a water-methanol cosolvent (Peng et al., 2014). The solubility of OFL decreased as the methanol volume fraction $\left(f_{\mathrm{c}}\right)$ increased. The sorption of OFL or NOR decreased as $f_{\mathrm{c}}$ increased. It is widely accepted that the effect of a cosolvent on the sorption of HOCs can be described by a log-linear cosolvency model (Rao et al., 1985), which is also suitable for describing the effect of cosolvents on OFL sorption. For NOR, however, the model and solubility change could not be used to describe its sorption. Thus, a log-linear cosolvency model cannot be applied as a general model to describe the effects of cosolvents on the adsorption of all organic contaminants.

\subsection{Metal ions}

The presence of metal ions makes the environmental behavior of organic contaminants more complicated because they can interact with contaminants and functional groups of CNPs. Metal ions $\left(\mathrm{Cu}^{2+}\right.$, 
$\mathrm{Pb}^{2+}$ and $\left.\mathrm{Cd}^{2+}\right)$ might form surface complexes with oxygen-containing functional groups of CNTs and thus the adsorption of organic contaminants, such as atrazine, 2,4,6-trichlorophenol on CNTs, may be suppressed (Chen G.C. et al., 2008; Chen et al., 2009). In other studies, the adsorption of diuron and dichlobenil on CNTs was inhibited by $\mathrm{Pb}^{2+}$ because a large hydration shell of $\mathrm{Pb}^{2+}$ formed on the CNT surface (Chen et al., 2011). However, $\mathrm{Cu}^{2+}$ increased tetracycline adsorption on CNTs because of cation bridging between $\mathrm{Cu}^{2+}$ and CNTs (Ji et al., 2010). Obviously, both increased and decreased adsorption of organic pollutants can be observed with the addition of metal ions, depending on environmental conditions. The net effect is the balance between the increased and decreased effects. Additionally, the aggregation of CNPs may be enhanced with increasing ionic strength. As a consequence, adsorption of organic contaminants is decreased on CNPs with highly compacted, aggregated structures (Zhang D. et al., 2010).

\subsection{Dissolved organic matter (DOM) or surfactants}

The coexistence of CNPs and DOM in the environment is widespread because of the increasing discharge of CNPs and the ubiquity of DOM. The presence of DOM might change the aggregation of CNTs and further change the number of available sites for adsorption of organic contaminants (Lin and Xing, 2008b). Two types of contrasting results have been reported. One is decreased adsorption of organic pollutants on CNPs. For example, adsorption of 1,3-dinitrobenzene, pyrene and 1,3,5-trinitrobenzene on CNTs decreased in the presence of DOM (Chen J.Y. et al., 2008; Zhang et al., 2012). Also, DOM and surfactants inhibited the adsorption of phenanthrene and naphthalene on CNTs (Hu et al., 2008; Wang et $a l ., 2008)$. The explanations for decreased adsorption generally were the occupation of adsorption sites of CNPs due to coating by DOM or surfactants, leading to decreased availability of CNP surfaces for adsorption of organic pollutants (Pan et al., 2013). Another result was increased adsorption of organic pollutants on CNPs. DOM and surfactants can effectively disperse CNPs by enhancing the hydrophilicity and steric repulsion of CNPs, consequently exposing more available adsorption sites (Hyung et al., 2007; Schierz and Zanker, 2009). CNPs generally are considered as a whole without separation of suspended and aggregated types. The contribution of suspended CNPs to the adsorption of organic chemicals has been ignored due to the lower amounts of suspended CNPs. Thus, in our recent study (Pan et al., 2013), we tried to separate the CNTs into suspended and aggregated types. The results indicated that the apparent overall adsorption of SMX was inhibited by DOM, but the sorption coefficients of SMX on DOM-suspended CNTs were up to two orders of magnitude higher than those on aggregated CNTs. Although the percentage mass of suspended CNTs was low (generally less than $1 \%$ ), their contribution to SMX adsorption was up to $20 \%$. The contrasting results of published studies may have resulted from ignorance of the contribution of suspended CNPs to adsorption. In other words, if the increased adsorption of organic pollutants due to a higher number of exposed sorption sites on suspended CNPs exceeds the decreased adsorption due to DOM coating, an apparent increase in overall adsorption will be observed, and vice versa. Obviously, suspended CNPs may have greater environmental impacts, such as enhancing the mobility, transport, and possibly exposure of organic contaminants. Thus, more attention should be paid to suspended CNPs.

\subsection{Perspectives}

The main interactions between organic contaminants and CNPs are hydrophobic, electrostatic, hydrogen bond, and $\pi-\pi$ interactions. These interactions and their strength are influenced by the surface properties and morphology of CNPs and the molecular size, structures, and functional groups of organic contaminants. For a given CNP, various mechanisms may simultaneously control the sorption progress of organic contaminants on CNPs, while the sorption controlling mechanisms may differ under different environmental conditions. Therefore, it is essential to investigate the primary sorption mechanisms or the relative contribution of different mechanisms to overall sorption. Normalization of adsorption coefficients by $K_{\mathrm{HW}}$ could be used to screen out the hydrophobic effects and comparison of the adsorption of various organic contaminants on a given CNP could provide important information on the contribution of different mechanisms. However, the relative contributions of other mechanisms, such as hydrogen bonding and $\pi-\pi$ interactions, to overall adsorption are 
still unclear. More experimental studies and theoretical simulations are required to quantify the relative contributions of these mechanisms to the sorption of organic contaminants on CNPs.

External surfaces, interstitial spaces, and grooves are the possible areas of CNPs available for organic chemical adsorption. The availability of these possible areas for adsorption can be altered by surface modifying chemicals, surface functional groups, and suspensions of CNPs. It is widely accepted that dispersion of CNP aggregates could expose more sorption sites, and thus enhance the adsorption of organic chemicals on CNPs. The common method to promote CNP dispersion is the surface modification by DOM or surfactants. However, this method may not be a viable way to enhance the sorption sites on CNP surfaces because the adsorbed DOM or surfactants could compete with organic contaminants on sorption sites, thereby resulting in decreased adsorption. Therefore, new methods need to be developed to expose available CNP sorption sites, such as selecting dispersion reagents that do not compete with organic chemicals on the CNP surface. Moreover, dispersed CNPs may result in higher environmental and health risks than undispersed CNPs when they are released into the environment. Extensive work is needed to evaluate the effects of the suspendability of CNPs in different environmental conditions on the sorption characteristics of organic contaminants.

\section{References}

Arnaldi, S., 2013. Exploring imaginative geographies of nanotechnologies in news media images of Italian nanoscientists. Technology in Society, 37:49-58. [doi:10. 1016/j.techsoc.2013.10.005]

Baughman, R.H., Zakhidov, A.A., De Heer, W.A., 2002. Carbon nanotubes - the route toward applications. Science, 297(5582):787-792. [doi:10.1126/science.1060 928]

Biesaga, M., Pyrzynska, K., 2006. The evaluation of carbon nanotubes as a sorbent for dicamba herbicide. Journal of Separation Science, 29(14):2241-2244. [doi:10.1002/ jssc.200600109]

Bouchard, D.C., 1998. Organic cosolvent effects on the sorption and transport of neutral organic chemicals. Chemosphere, 36(8):1883-1892. [doi:10.1016/S00456535(97)10065-0]

Chen, G.C., Shan, X.Q., Wang, Y.S., et al., 2008. Effects of copper, lead, and cadmium on the sorption and desorption of atrazine onto and from carbon nanotubes. Environmental Science \& Technology, 42(22):8297-8302. [doi:10.1021/es801376w]
Chen, G.C., Shan, X.Q., Wang, Y.S., et al., 2009. Adsorption of 2,4,6-trichlorophenol by multi-walled carbon nanotubes as affected by $\mathrm{Cu}(\mathrm{II})$. Water Research, $\mathbf{4 3}(9)$ : 2409-2418. [doi:10.1016/j.watres.2009.03.002]

Chen, G.C., Shan, X.Q., Pei, Z.G., et al., 2011. Adsorption of diuron and dichlobenil on multiwalled carbon nanotubes as affected by lead. Journal of Hazardous Materials, 188(1-3):156-163. [doi:10.1016/j.jhazmat.2011.01.095]

Chen, J.Y., Chen, W., Zhu, D., 2008. Adsorption of nonionic aromatic compounds to single-walled carbon nanotubes: effects of aqueous solution chemistry. Environmental Science \& Technology, 42(19):7225-7230. [doi:10.1021/ es801412j]

Chen, W., Duan, L., Zhu, D., 2007. Adsorption of polar and nonpolar organic chemicals to carbon nanotubes. Environmental Science \& Technology, 41(24):8295-8300. [doi:10.1021/es071230h]

Chen, W., Duan, L., Wang, L.L., et al., 2008. Adsorption of hydroxyl- and amino-substituted aromatics to carbon nanotubes. Environmental Science \& Technology, 42(18): 6862-6868. [doi:10.1021/es8013612]

Cheng, X.K., Kan, A.T., Tomson, M.B., 2004. Naphthalene adsorption and desorption from aqueous $\mathrm{C}_{60}$ fullerene. Journal of Chemical \& Engineering Data, 49(3):675-683. [doi:10.1021/je030247m]

Cheng, X.K., Kan, A., Tomson, M., 2005. Uptake and sequestration of naphthalene and 1,2-dichlorobenzene by $\mathrm{C}_{60}$. Journal of Nanoparticle Research, 7(4-5):555-567. [doi:10.1007/s11051-005-5674-z]

Cho, H.H., Smith, B.A., Wnuk, J.D., et al., 2008. Influence of surface oxides on the adsorption of naphthalene onto multiwalled carbon nanotubes. Environmental Science \& Technology, 42(8):2899-2905. [doi:10.1021/es702363e]

Chorover, J., Amistadi, M.K., Burgos, W.D., et al., 1999. Quinoline sorption on kaolinite-humic acid complexes. Soil Science Society of American Journal, 63(4):850-857. [doi:10.2136/sssaj1999.634850x]

Clark II, C.J., Rao, P.S.C., Annable, M.D., 2003. Degradation of perchloroethylene in cosolvent solutions by zerovalent iron. Journal of Hazardous Materials, 96(1):65-78. [doi:10.1016/S0304-3894(02)00162-0]

Delgado, R., Carlo, G., 2013. Nanotechnology in Mexico: global trends and national implications for policy and regulatory issues. Technology in Society, 37:4-15. [doi:10.1016/j.techsoc.2013.09.005]

Fagan, S.B., Souza Filho, A.G., Lima, J.O.G., et al., 2004. 1,2-dichlorobenzene interacting with carbon nanotubes. Nano Letters, 4(7):1285-1288. [doi:10.1021/n10493895]

Frimmel, F.H., Niessner, R., Baumann, T., 2010. Nanoparticles in Groundwater-Occurrence and Applications. Nanoparticles in the Water Cycle, Springer Berlin Heidelberg, p.23-34.

Gotovac, S., Hattori, Y., Noguchi, D., et al., 2006. Phenanthrene adsorption from solution on single wall carbon nanotubes. The Journal of Physical Chemistry B, 110(33):16219-16224. [doi:10.1021/jp0611830]

Gotovac, S., Honda, H., Hattori, Y., et al., 2007a. Effect of nanoscale curvature of single-walled carbon nanotubes on 
adsorption of polycyclic aromatic hydrocarbons. Nano Letters, 7(3):583-587. [doi:10.1021/n10622597]

Gotovac, S., Song, L., Kanoh, H., et al., 2007b. Assembly structure control of single wall carbon nanotubes with liquid phase naphthalene adsorption. Colloids and Surfaces A: Physicochemical and Engineering Aspects, 300(1-2):117-121. [doi:10.1016/j.colsurfa.2006.10.035]

Gotovac, S., Yang, C.M., Hattori, Y., et al., 2007c. Adsorption of polyaromatic hydrocarbons on single wall carbon nanotubes of different functionalities and diameters. Journal of Colloid and Interface Science, 314(1):18-24. [doi:10.1016/j.jcis.2007.04.080]

Gwinn, M.R., Vallyathan, V., Nriagu, J.O., 2011. Nanotechnology: Human Safety Issues, Research Gaps and Potential Beneficial Opportunities. Encyclopedia of Environmental Health. Elsevier, Burlington, p.24-32.

Handy, R., Owen, R., Valsami-Jones, E., 2008. The ecotoxicology of nanoparticles and nanomaterials: current status, knowledge gaps, challenges, and future needs. Ecotoxicology, 17(5):315-325. [doi:10.1007/s10646-0080206-0]

Hu, J., Shao, D.D., Chen, C.L., et al., 2010. Plasma-induced grafting of cyclodextrin onto multiwall carbon nanotube/ iron oxides for adsorbent application. The Journal of Physical Chemistry B, 114(20):6779-6785. [doi:10.1021/ jp911424k]

Hu, X.L., Liu, J.L., Mayer, P., et al., 2008. Impacts of some environmentally relevant parameters on the sorption of polycyclic aromatic hydrocarbons to aqueous suspensions of fullerene. Environmental Toxicology and Chemistry 27(9):1868-1874. [doi:10.1897/08-009.1]

Hyung, H., Fortner, J.D., Hughes, J.B., et al., 2007. Natural organic matter stabilizes carbon nanotubes in the aqueous phase. Environmental Science \& Technology, 41(1): 179-184. [doi:10.1021/es061817g]

Iijima, S., Ichihashi, T., 1993. Single-shell carbon nanotubes of 1-nm diameter. Nature, 363(6430):603-605. [doi:10. 1038/363603a0]

Ji, L.L., Chen, W., Zheng, S.R., et al., 2009. Adsorption of sulfonamide antibiotics to multiwalled carbon nanotubes. Langmuir, 25(19):11608-11613. [doi:10.1021/la901 5838]

Ji, L.L., Chen, W., Bi, J., et al., 2010. Adsorption of tetracycline on single-walled and multi-walled carbon nanotubes as affected by aqueous solution chemistry. Environmental Toxicology and Chemistry, 29(12):27132719. [doi:10.1002/etc.350]

Klaine, S.J., Alvarez, P.J.J., Batley, G.E., et al., 2008. Nanomaterials in the environment: behavior, fate, bioavailability, and effects. Environmental Toxicology and Chemistry, 27(9):1825-1851. [doi:10.1897/08-090.1]

Kulshrestha, P., Giese, R.F., Aga, D.S., 2004. Investigating the molecular interactions of oxytetracycline in clay and organic matter: insights on factors affecting its mobility in soil. Environmental Science \& Technology, 38(15):40974105. [doi:10.1021/es034856q]

Lam, C.W., James, J.T., Mccluskey, R., et al., 2006. A review of carbon nanotube toxicity and assessment of potential occupational and environmental health risks. Critical Reviews in Toxicology, 36(3):189-217. [doi:10.1080/ 10408440600570233]

Li, X.N., Zhao, H.M., Quan, X., et al., 2011. Adsorption of ionizable organic contaminants on multi-walled carbon nanotubes with different oxygen contents. Journal of Hazardous Materials, 186(1):407-415. [doi:10.1016/j. jhazmat.2010.11.012]

Liao, Q., Sun, J., Gao, L., 2008. The adsorption of resorcinol from water using multi-walled carbon nanotubes. Colloids and Surfaces A: Physicochemical and Engineering Aspects, 312(2-3):160-165. [doi:10.1016/j.colsurfa.2007. 06.045]

Lin, D.H., Xing, B.S., 2008a. Adsorption of phenolic compounds by carbon nanotubes: role of aromaticity and substitution of hydroxyl groups. Environmental Science \& Technology, 42(19):7254-7259. [doi:10.1021/es 801297u]

Lin, D.H., Xing, B.S., 2008b. Tannic acid adsorption and its role for stabilizing carbon nanotube suspensions. Environmental Science \& Technology, 42(16):5917-5923. [doi:10.1021/es800329c]

Liu, C.H., Li, J.J., Zhang, H.L., et al., 2008. Structure dependent interaction between organic dyes and carbon nanotubes. Colloids and Surfaces A: Physicochemical and Engineering Aspects, 313-314:9-12. [doi:10. 1016/j.colsurfa.2007.04.062]

Liu, X., Wang, X.C., Tan, F., et al., 2012. An electrochemically enhanced solid-phase microextraction approach based on molecularly imprinted polypyrrole/ multi-walled carbon nanotubes composite coating for selective extraction of fluoroquinolones in aqueous samples. Analytica Chimica Acta, 727:26-33. [doi:10. 1016/j.aca.2012.03.054]

Lu, C., Chung, Y.L., Chang, K.F., 2005. Adsorption of trihalomethanes from water with carbon nanotubes. Water Research, 39(6):1183-1189. [doi:10.1016/j.watres. 2004.12.033]

MacKay, A.A., Vasudevan, D., 2012. Polyfunctional ionogenic compound sorption: challenges and new approaches to advance predictive models. Environmental Science \& Technology, 46(17):9209-9223. [doi:10.1021/es301036t]

Masciangioli, T., Zhang, W.X., 2003. Environmental technologies at the nanoscale. Environmental Science \& Technology, 37(5):102A-108A. [doi:10.1021/es0323998]

Pan, B., Xing, B.S., 2008. Adsorption mechanisms of organic chemicals on carbon nanotubes. Environmental Science \& Technology, 42(24):9005-9013. [doi:10.1021/es $801777 \mathrm{n}]$

Pan, B., Lin, D.H., Mashayekhi, H., et al., 2008. Adsorption and hysteresis of bisphenol A and 17 $\alpha$-ethinyl estradiol on carbon nanomaterials. Environmental Science \& Technology, 42(15):5480-5485. [doi:10.1021/es8001184]

Pan, B., Zhang, D., Li, H., et al., 2013. Increased adsorption of sulfamethoxazole on suspended carbon nanotubes by dissolved humic acid. Environmental Science \& Technology, 47(14):7722-7728. [doi:10.1021/es4008933]

Park, H.R., Kim, T.H., Bark, K.M., 2002. Physicochemical 
properties of quinolone antibiotics in various environments. European Journal of Medicinal Chemistry, 37(6): 443-460. [doi:10.1016/S0223-5234(02)01361-2]

Peng, H.B., Pan, B., Wu, M., et al., 2012a. Adsorption of ofloxacin on carbon nanotubes: solubility, $\mathrm{pH}$ and cosolvent effects. Journal of Hazardous Materials, 211-212:342-348. [doi:10.1016/j.jhazmat.2011.12.063]

Peng, H.B., Pan, B., Wu, M., et al., 2012b. Adsorption of ofloxacin and norfloxacin on carbon nanotubes: hydrophobicity- and structure-controlled process. Journal of Hazardous Materials, 233-234:89-96. [doi:10.1016/j. jhazmat.2012.06.058]

Peng, H.B., Li, H., Wang, C., et al., 2014. Sorption and solubility of ofloxacin and norfloxacin in water-methanol cosolvent. Chemosphere, 103:322-328. [doi:10.1016/j. chemosphere. 2013.12.025]

Peng, X., Li, Y.H., Luan, Z.K., et al., 2003. Adsorption of 1,2-dichlorobenzene from water to carbon nanotubes. Chemical Physics Letters, 376(1-2):154-158. [doi:10. 1016/S0009-2614(03)00960-6]

Petersen, E.J., Zhang, L., Mattison, N.T., et al., 2011. Potential release pathways, environmental fate, and ecological risks of carbon anotubes. Environmental Science \& Technology, 45(23):9837-9856. [doi:10.1021/es201579y]

Piao, L.Y., Liu, Q.R., Li, Y.D., et al., 2008. Adsorption of L-phenylalanine on single-walled carbon nanotubes. The Journal of Physical Chemistry C, 112(8):2857-2863. [doi:10.1021/jp077047s]

Popov, V.N., 2004. Carbon nanotubes: properties and application. Materials Science and Engineering: $R$ : Reports, 43(3):61-102. [doi:10.1016/j.mser.2003.10.001]

Rao, P.S.C., Homsby, A.G., Kilcrease, D.P., et al., 1985. Sorption and transport of hydrophobic organic chemicals in aqueous and mixed solvent systems: model development and preliminary evaluation. Journal of Environmental Quality, 14(3):376-383. [doi:10.2134/jeq 1985.00472425001400030014x]

Reilly, R.M., 2007. Carbon nanotubes: potential benefits and risks of nanotechnology in nuclear medicine. Journal of Nuclear Medicine, 48(7):1039-1042. [doi:10.2967/ jnumed.107.041723]

Reinsch, B.C., Forsberg, B., Penn, R.L., et al., 2010. Chemical transformations during aging of zerovalent iron nanoparticles in the presence of common groundwater dissolved constituents. Environmental Science \& Technology, 44(9): 3455-3461. [doi:10.1021/es902924h]

Ren, X.M., Chen, C.L., Nagatsu, M., et al., 2011. Carbon nanotubes as adsorbents in environmental pollution management: a review. Chemical Engineering Journal, 170(2-3):395- 410. [doi:10.1016/j.cej.2010.08.045]

Schierz, A., Zanker, H., 2009. Aqueous suspensions of carbon nanotubes: surface oxidation, colloidal stability and uranium sorption. Environmental Pollution, 157(4):10881094. [doi:10.1016/j.envpol.2008.09.045]

Shao, D.D., Hu, J., Chen, C.L., et al., 2010a. Polyaniline multiwalled carbon nanotube magnetic composite prepared by plasma- induced graft technique and its application for removal of aniline and phenol. The Journal of Physical
Chemistry C, 114(49):21524-21530. [doi:10.1021/ jp107492g]

Shao, D.D., Sheng, G.D., Chen, C.L., et al., 2010b. Removal of polychlorinated biphenyls from aqueous solutions using $\beta$-cyclodextrin grafted multiwalled carbon nanotubes. Chemosphere, 79(7):679-685. [doi:10.1016/j. chemosphere.2010.03.008]

Shen, X.E., Shan, X.Q., Dong, D.M., et al., 2009. Kinetics and thermodynamics of sorption of nitroaromatic compounds to as-grown and oxidized multiwalled carbon nanotubes. Journal of Colloid and Interface Science, 330(1):1-8. [doi:10.1016/j.jcis.2008.10.023]

Sheng, G.D., Shao, D.D., Ren, X.M., et al., 2010. Kinetics and thermodynamics of adsorption of ionizable aromatic compounds from aqueous solutions by as-prepared and oxidized multiwalled carbon nanotubes. Journal of Hazardous Materials, 178(1-3):505-516. [doi:10.1016/j. jhazmat.2010.01.110]

Tasis, D., Tagmatarchis, N., Bianco, A., et al., 2006. Chemistry of carbon nanotubes. Chemical Reviews, 106(3): 1105-1136. [doi:10.1021/cr050569o]

Tong, Z., Bischoff, M., Nies, L., et al., 2007. Impact of fullerene $\left(\mathrm{C}_{60}\right)$ on a soil microbial community. Environmental Science \& Technology, 41(8):2985-2991. [doi:10. 1021/es0619531]

Tournus, F., Charlier, J.C., 2005. Ab initio study of benzene adsorption on carbon nanotubes. Physical Review B, 71(16):165421. [doi:10.1103/PhysRevB.71.165421]

Tournus, F., Latil, S., Heggie, M.I., et al., 2005. $\pi$-stacking interaction between carbon nanotubes and organic molecules. Physical Review B, 72(7):075431. [doi:10. 1103/PhysRevB.72.075431]

Umbuzeiro, G.A., Coluci, V.R., Honorio, J.G., et al., 2011. Understanding the interaction of multi-walled carbon nanotubes with mutagenic organic pollutants using computational modeling and biological experiments. TrAC Trends in Analytical Chemistry, 30(3):437-446. [doi:10.1016/j.trac.2010.11.013]

van Wieren, E.M., Seymour, M.D., Peterson, J.W., 2012. Interaction of the fluoroquinolone antibiotic, ofloxacin, with titanium oxide nanoparticles in water: adsorption and breakdown. Science of The Total Environment, 441:1-9. [doi:10.1016/j.scitotenv.2012.09.067]

Vermisoglou, E.C., Georgakilas, V., Kouvelos, E., et al., 2007. Sorption properties of modified single-walled carbon nanotubes. Microporous and Mesoporous Materials, 99(1-2):98-105. [doi:10.1016/j.micromeso.2006.07.035]

Wang, X.L., Lu, J.L., Xing, B.S., 2008. Sorption of organic contaminants by carbon nanotubes: influence of adsorbed organic matter. Environmental Science \& Technology, 42(9):3207-3212. [doi:10.1021/es702971g]

Wang, Y.F., Shu, L., Jegatheesan, V., et al., 2010. Removaland adsorption of diuron through nanofiltration membrane: the effects of ionic environment and operating pressures. Separation and Purification Technology, 74(2):236-241. [doi:10.1016/j.seppur.2010.06.011]

Wang, Z.Y., Yu, X.D., Pan, B., et al., 2010. Norfloxacin sorption and its thermodynamics on surface-modified 
carbon nanotubes. Environmental Science \& Technology, 44(3): 978-984. [doi:10.1021/es902775u]

Wigginton, N.S., Haus, K.L., Hochella, M.F.Jr, 2007. Aquatic environmental nanoparticles. Journal of Environmental Monitoring, 9(12):1306-1316. [doi:10.1039/b712709j]

Woods, L.M., Badescu, S.C., Reinecke, T.L., 2007. Adsorption of simple benzene derivatives on carbon nanotubes. Physical Review B, 75(15):155415. [doi:10. 1103/PhysRevB.75.155415]

Yang, K., Xing, B.S., 2007. Desorption of polycyclic aromatic hydrocarbons from carbon nanomaterials in water. Environmental Pollution, 145(2):529-537. [doi:10.1016/j. envpol.2006.04.020]

Yang, K., Zhu, L.Z., Xing, B.S., 2006. Adsorption of polycyclic aromatic hydrocarbons by carbon nanomaterials. Environmental Science \& Technology, 40(6):1855-1861. [doi:10.1021/es052208w]

Yang, K., Wu, W.H., Jing, Q.F., et al., 2008. Aqueous adsorption of aniline, phenol, and their substitutes by multi-walled carbon nanotubes. Environmental Science \& Technology, 42(21):7931-7936. [doi:10.1021/es801463v]

Yang, W.B., Lu, Y.P., Zheng, F.F., et al., 2012. Adsorption behavior and mechanisms of norfloxacin onto porous resins and carbon nanotube. Chemical Engineering Journal, 179: 112-118. [doi:10.1016/j.cej.2011.10.068]

Yang, Y.N., Chun, Y., Sheng, G.Y., et al., 2004. pH-dependence of pesticide adsorption by wheat-residue-derived black carbon. Langmuir, 20(16):6736-6741. [doi:10.1021/ la049363t]

Zhang, D., Pan, B., Zhang, H., et al., 2010. Contribution of different sulfamethoxazole species to their overall adsorption on functionalized carbon nanotubes. Environmental
Science \& Technology, 44(10):3806-3811. [doi:10.1021/ es903851q]

Zhang, S.J., Shao, T., Bekaroglu, S.S.K., et al., 2009. The impacts of aggregation and surface chemistry of carbon nanotubes on the adsorption of synthetic organic compounds. Environmental Science \& Technology, 43(15): 5719-5725. [doi:10.1021/es900453e]

Zhang, S.J., Shao, T., Bekaroglu, S.S.K., et al., 2010. Adsorption of synthetic organic chemicals by carbon nanotubes: effects of background solution chemistry. Water Research, 44(6):2067-2074. [doi:10.1016/j.watres. 2009.12.017]

Zhang, X., Pan, B., Yang, K., et al., 2010. Adsorption of sulfamethoxazole on different types of carbon nanotubes in comparison to other natural adsorbents. Journal of Environmental Science and Health, Part A, 45(12): 1625-1634. [doi:10.1080/10934529.2010.506127]

Zhang, X., Kah, M., Jonker, M.T.O., et al., 2012. Dispersion state and humic acids concentration-dependent sorption of pyrene to carbon nanotubes. Environmental Science \& Technology, 46(13):7166-7173. [doi:10.1021/es300 645m]

Zhao, J.J., Buldum, A., Han, J., et al., 2002. Gas molecule adsorption in carbon nanotubes and nanotube bundles. Nanotechnology, 13(2):195-200. [doi:10.1088/0957$4484 / 13 / 2 / 312]$

Zou, M., Zhang, J., Chen, J., et al., 2012. Simulating adsorption of organic pollutants on finite $(8,0)$ singlewalled carbon nanotubes in water. Environmental Science \& Technology, 46(16):8887-8894. [doi:10.1021/es30 1370f]

\section{中文概要:}

本文题目: 有机污染物和碳纳米颗粒: 吸附机理及影响因素

Organic contaminants and carbon nanoparticles: sorption mechanisms and impact parameters

研究目的：碳纳米颗粒由于其独特的优良性能被广泛应用，从而不可避免地进入环境。进入环境的碳纳 米颗粒与有机污染物有很强的相互作用，并且碳纳米颗粒对有机污染物的吸附可能会影响污 染物的环境风险和迁移。因此, 本研究总结了目前有机污染物在碳纳米颗粒上吸附的研究进 展, 为有机污染物及碳纳米颗粒的环境行为研究及风险评价提供重要信息。

重要结论: 有机污染物和碳纳米颗粒的主要相互作用有憎水性、静电、氢键和 $\pi-\pi$ 作用, 这些作用及它 们的强度受碳纳米颗粒的表面性质、形态及有机污染物的分子大小、结构和官能团等影响。 不同的吸附机理可能同时控制有机物在碳纳米颗粒上的吸附过程，而且在不同的环境条件下 吸附控制机理不同。区分吸附控制机理和影响因素的研究对预测有机污染物和碳纳米颗粒的 环境行为和风险非常重要。

关键词组: 有机污染物; 环境行为; 碳纳米颗粒; 相互作用机理 